\title{
RhMKK9, a rose MAP KINASE KINASE gene, is involved in rehydration-triggered ethylene production in rose gynoecia
}

Jiwei Chen ${ }^{1,2+}$, Qian Zhang ${ }^{1,2 \dagger}$, Qigang Wang ${ }^{3}$, Ming Feng ${ }^{1,2}$, Yang Li ${ }^{1,2}$, Yonglu Meng ${ }^{1,4}$, Yi Zhang ${ }^{1,2}$, Guoqin Liu ${ }^{1,2}$, Zhimin $\mathrm{Ma}^{1,2}$, Hongzhi Wu${ }^{5}$, Junping Gao ${ }^{1,2}$ and Nan Ma, ${ }^{1,2^{*}}$

\begin{abstract}
Background: Flower opening is an important process in the life cycle of flowering plants and is influenced by various endogenous and environmental factors. Our previous work demonstrated that rose (Rosa hybrida) flowers are highly sensitive to dehydration during flower opening and the water recovery process after dehydration induced ethylene production rapidly in flower gynoecia. In addition, this temporal- and spatial-specific ethylene production is attributed to a transient but robust activation of the rose MAP KINASE6-ACC SYNTHASE1 (RhMPK6RhACS1) cascade in gynoecia. However, the upstream component of RhMPK6-RhACS1 is unknown, although RhMKK9 (MAP KINASE KINASE9), a rose homologue of Arabidopsis MKK9, could activate RhMPK6 in vitro. In this study, we monitored RhMKK2/4/5/9 expression, the potential upstream kinase to RhMPK6, in rose gynoecia during dehydration and rehydration.
\end{abstract}

Results: We found only RhMKK9 was rapidly and strongly induced by rehydration. Silencing of RhMKK9 significantly decreased rehydration-triggered ethylene production. Consistently, the expression of several ethylene-responsive genes was down regulated in the petals of RhMKKG-silenced flowers. Moreover, we detected the DNA methylation level in the promoter and gene body of RhMKK9 by Chop-PCR. The results showed that rehydration specifically elevated the DNA methylation level on the RhMKK9 gene body, whereas it resulted in hypomethylation in its promoter.

Conclusions: Our results showed that RhMKK9 possibly acts as the upstream component of the RhMKK9-RhMPK6RhACS1 cascade and is responsible for water recovery-triggered ethylene production in rose gynoecia, and epigenetic DNA methylation is involved in the regulation of RhMKK9 expression by rehydration.

Keywords: Rose flower, Gynoecia, RhMKK9, Rehydration, Ethylene biosynthesis, DNA methylation

\section{Background}

Plants are exposed to various abiotic and biotic stresses because of their sessile life style. Therefore, for improved survival, plants develop a system that can rapidly sense signals from a changing environment and respond adaptively and/or defensively by modulating the internal

\footnotetext{
*Correspondence: ma_nan@cau.edu.cn

${ }^{\dagger}$ Equal contributors

'Department of Ornamental Horticulture, China Agricultural University, Beijing 100193, China

${ }^{2}$ Beijing Key Laboratory of Development and Quality Control of Ornamental Crops, China Agricultural University, No. 2 Yuanmingyuan West Road, Haidian District, Beijing 100193, China

Full list of author information is available at the end of the article
}

physiological, biochemical, and molecular processes $[1,2]$. For most crops, water deficit causes a major limitation to the yield. It has been well documented that water deficit results in several physiological changes, including wilting, stomatal closure, hormone imbalance, and suppression of cell growth and photosynthesis [3, 4]. After dehydration, plants are able to recover quickly once water is available again via the rehydration process [5-7].

Although signal reception and the transduction pathway of dehydration have been extensively reported, they remain largely unknown for the rehydration process. Using a DNA microarray, Oono et al. [5] found that rehydration-responsive genes included genes related to 
both stressed status release and growth recovery in Arabidopsis. In addition, ethylene-biosynthetic genes and genes responsive to jasmonic acid, gibberellin, and auxin were activated by rehydration, suggesting hormone balance is involved in the water recovery of plants.

In plants, the mitogen-activated protein kinase (MAPK) cascade plays an essential role in the signaling pathway of multiple abiotic and biotic stress cues [1, 2, 8-11]. The MAPK cascade is initiated by a mitogen-activated protein kinase kinase kinase (MAPKKK, MAP3K, or MEKK), which reversibly phosphorylates a mitogen-activated protein kinase kinase (MAPKK, MAP2K, or MKK) and subsequently phosphorylates the mitogen-activated protein kinase (MAPK or MPK). Then, MPK phosphorylates its downstream target proteins to modulate various developmental and physiological processes [12]. In Arabidopsis, several components of the MAPK cascade, such as MPK4 and MPK6, were reported to be activated by drought $[13,14]$; a recent report showed that MPK6 could be activated by drought, but inactivated by rehydration in Arabidopsis seedlings [15].

Cut roses (Rosa hybrida) are an important ornamental crop globally. Dehydration is a considerable postharvest problem for cut roses because their market supply is highly dependent on long-distance transportation, resulting in severe dehydration for this duration. Recently, we reported that in rose (R. hybrida) flowers, rehydration following dehydration triggered rapid, but transient, ethylene production in the gynoecia, namely all the carpels and pistils in a flower [7]. During dehydration and rehydration, the protein level of a specific MAP kinase, RhMPK6, was maintained at a constant high level. However, RhMPK6 activity was only detected within $1 \mathrm{~h}$ of rehydration [16]. Furthermore, activated RhMPK6 phosphorylated and stabilised RhACS1, a rate-limiting enzyme of ethylene biosynthesis, and resulted in an ethylene burst in gynoecia. Ethylene plays an important role in flower opening and senescence in roses [17-20]; thus, we speculated that the RhMPK6RhACS1 module might be crucial to sense the rehydration signal and transmit it to ethylene to regulate flower opening and senescence in roses.

Previously, we found that a MAPKK protein, RhMKK9, could phosphorylate the RhMPK6 protein in vitro [16]. However, to date it is unknown whether RhMKK9 is the actual upstream component activating RhMPK6 in gynoecia during rehydration. In the present study, we isolated the possible MAPK kinases upstream from RhMPK6 from roses and monitored their expression pattern during dehydration and rehydration. We found that $R h M K K 9$ is the specific MAPK kinase that phosphorylates RhMPK6 and is responsible for the rehydrationinduced ethylene production in gynoecia. Furthermore, methylation-sensitive PCR showed that DNA methylation of the promoter of $R h M K K 9$ contributes to rehydrationinduced upregulation of $R h M K K 9$ expression.

\section{Results \\ RhMKK9 expression is rapidly and strongly induced by dehydration in rose gynoecia}

We previously reported that ethylene production could be rapidly but transiently induced by rehydration in rose gynoecia when the flowers were subjected to dehydrationrehydration treatment [7]. Moreover, temporal- and spatial-specific activation of an RhMPK6-RhACS1 cascade is responsible for this rehydration-induced ethylene production [16].

In Arabidopsis, MPK6 could be activated by MAPK kinases MKK2/4/5/9 [21]. Thus, we searched the rose homologues of AtMKK2, AtMKK4, AtMKK5, and AtMKK9 in a rose transcriptome database [22], and cloned their full-length sequences. We designated these sequences as RhMKK2 (RU26187, GenBank Acc. No. KP269070), RhMKK4 (RU27106, GenBank Acc. No. KP269071), RhMKK5 (RU11454, GenBank Acc. No. KP269072), and RhMKK9 (RU24635, GenBank Acc. No. KP269073), respectively (Fig. 1; Additional file 1: Figure S1). The fulllength cDNA of RhMKK9 is $1,367 \mathrm{bp}$ and contains a 975-bp open reading frame flanking with a 59-bp 5'untranslated region (UTR) and a 333-bp 3'-UTR. For RhMKK2, RhMKK4, and RhMKK5, the cDNA fulllength was 1453, 1522, and $1508 \mathrm{bp}$, respectively (Additional file 1: Table S1).

To identify which MKK gene was the major contributor to rehydration-induced ethylene biosynthesis in rose gynoecia, we firstly detected the expression level of all four genes in response to dehydration and rehydration in gynoecia. RhMKK4 expression was induced by $24 \mathrm{~h}$ dehydration in gynoecia, whereas expression of $R h M K K 2$ and $R h M K K 9$ was almost not affected. When the flowers were subjected to rehydration, $R h M K K 2 / 4 / 5$ transcription appeared to be slightly induced $30 \mathrm{~min}$ after rehydration. However, RhMKK 9 expression was rapidly and strongly induced within $30 \mathrm{~min}$ after rehydration. After $12 \mathrm{~h}$ of rehydration, RhMKK9 transcription decreased to a relative low level (Fig. 2). Meanwhile, RhMPK6 expression was retained at a relatively constant level during dehydration and rehydration, consistent with RhMPK6 protein accumulation in our previous report [16]. Furthermore, rehydration-induced activation of RhMPK6-RhACS1 and consequently ethylene biosynthesis occurred during $0.5-1 \mathrm{~h}$ of rehydration and then dropped quickly [16]. According to the timing of the expression, we speculated that RhMKK9 might be the MAPK kinase responsible for the activation of the RhMPK6-RhACS1 cascade in rose gynoecia. 

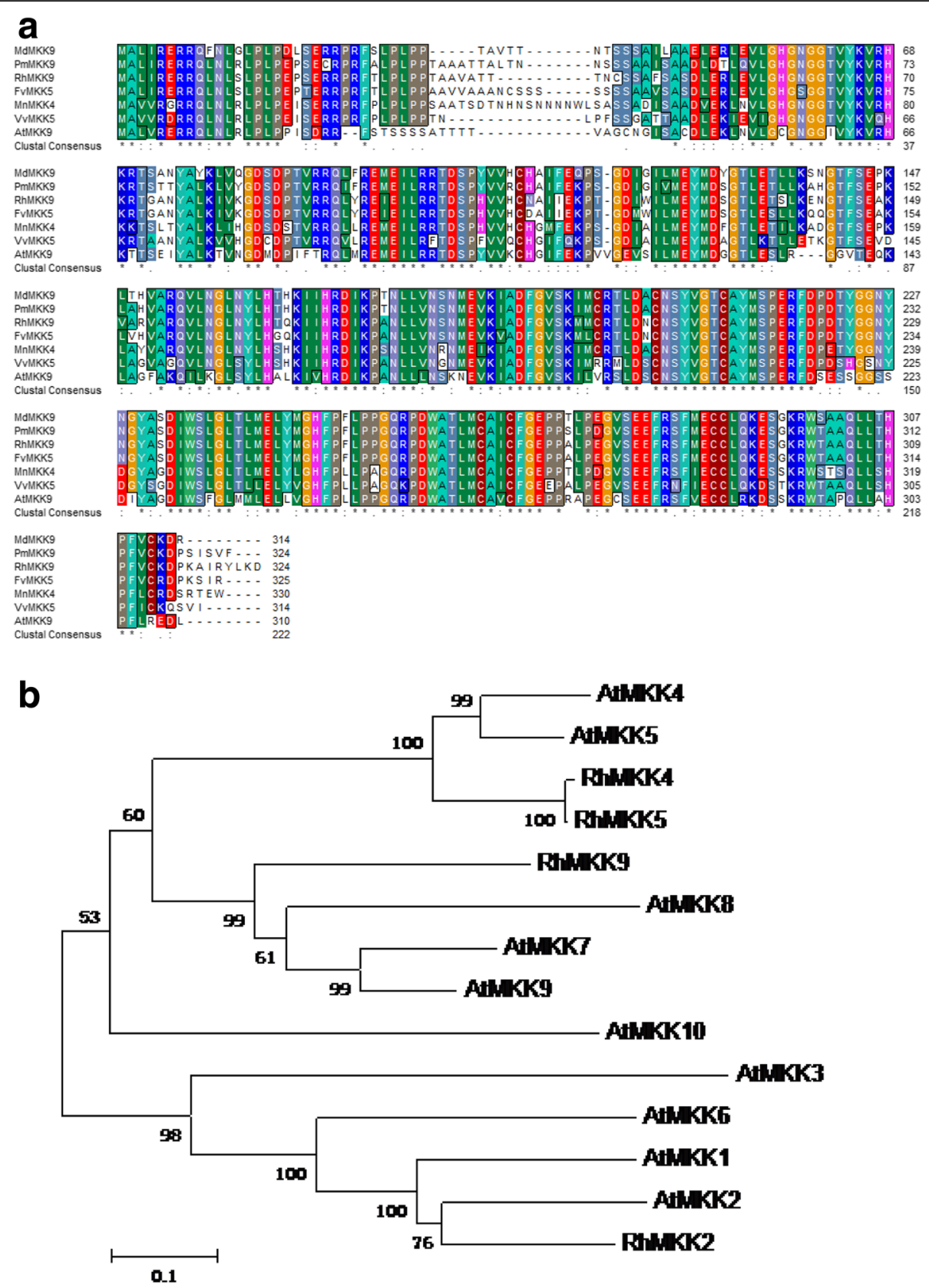

Fig. 1 Alignment (a) and phylogenetic tree assay (b) of RhMKK9. A phylogenetic tree was constructed using the predicted RhMKK2/4/5/9 amino acid sequences and MKK homologues from various plant species. The tree was constructed using MEGA 5.2. Bootstrap values indicate the divergence of each branch and the scale bar represents the branch length at 0.1 substitutions per site

Silencing of RhMKK9 suppressed ethylene production and petal senescence in rose flowers after dehydration and rehydration treatment

To further confirm the potential role of $R h M K K 9$ in rehydration-induced ethylene production in gynoecia, we silenced $R h M K K 9$ - using a virus-induced gene silencing (VIGS) approach. An RhMKK9-specific fragment was chosen to construct the TRV2-MKK9 vector to avoid cross silencing of other MKK genes. We screened positive $R h M K K 9$-silenced flowers by detecting RNA1, RNA2, and RhMKK9 transcription. Both RNA1 and RNA2 transcripts were detected in $\sim 28 \%$ flowers, indicating that TRV successfully infected these flowers. RT-PCR analysis revealed that RhMKK9 expression was significantly reduced in gynoecia of $R h M K K 9$-silenced flowers than those of the TRV2 controls, especially at $1 \mathrm{~h}$ after rehydration treatment (Fig. 3a). In addition, we detected $R h M K K 2 / 4 / 5$ expression in $R h M K K 9$-silenced 


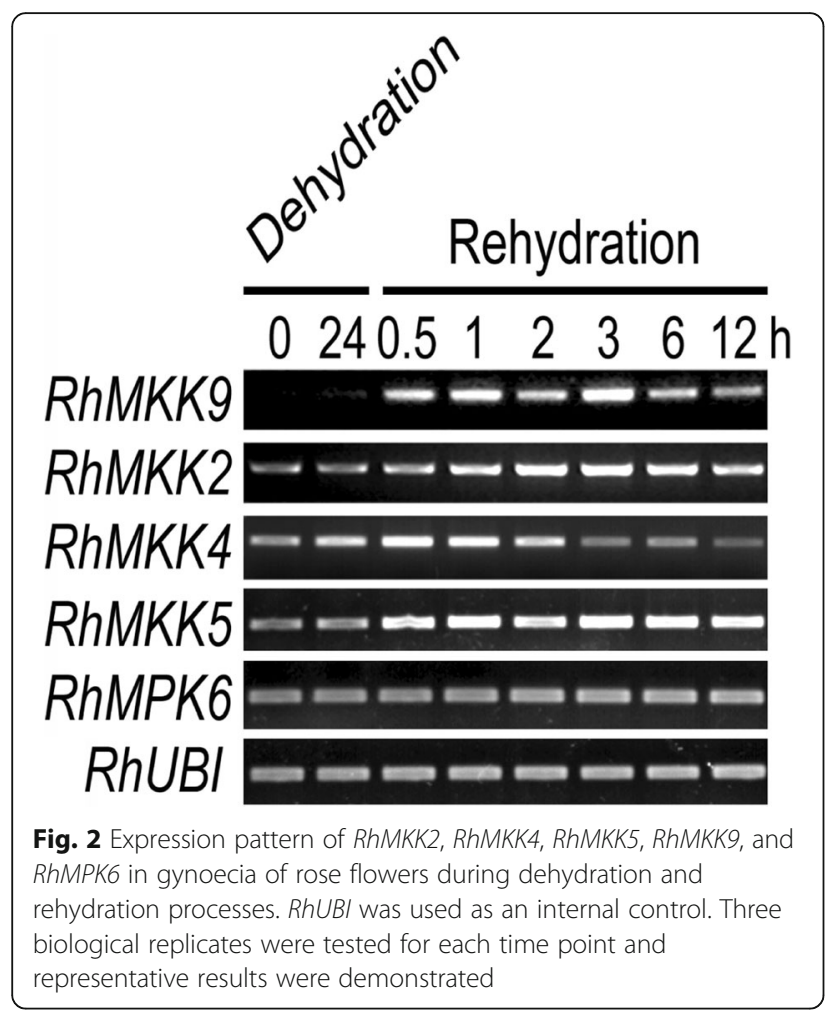

flowers to confirm whether their expression was affected by silencing $R h M K K 9$. As expected, RhMKK $2 / 4$ expression in $R h M K K 9$-silenced samples was similar to that in the TRV2 controls (Fig. 3a), indicating that silencing of $R h M K K 9$ did not influence the transcript accumulation of $R h M K K 2 / 4$. Interestingly, $R h M K K 5$ transcription appeared to reduce in the silenced flowers relative to the controls. Because RhMKK9 shared 54\% homology of the nucleotide sequence with $R h M K K 5$, we assumed that the relatively low level of $R h M K K 5$ should not result from the $R h M K K 9$ fragment triggered cross silencing, which requires a high nucleotide sequence homology (>90\%).

In addition, we monitored the accumulation pattern of RhMPK6 transcript and protein, as well as the kinase activity of RhMPK6 in RhMKK9-silenced flowers. We tested the RhMPK6 activity and protein level after 30 min of rehydration and RhACS1 protein level after $1 \mathrm{~h}$ of rehydration, respectively. This was based on the results from our previous study, which showed that the highest level of RhMPK6 activity and RhACS1 protein appeared at $30 \mathrm{~min}$ and $1 \mathrm{~h}$ of rehydration, respectively [16]. As expected, the transcript and protein level of RhMPK6 were not affected by RhMKK9 silencing. However, phos-tag SDS-PAGE demonstrated that RhMKK9 silencing largely weakened RhMPK6 phosphorylation during rehydration (Fig. $3 \mathrm{~b}$ ). Thus, we considered that

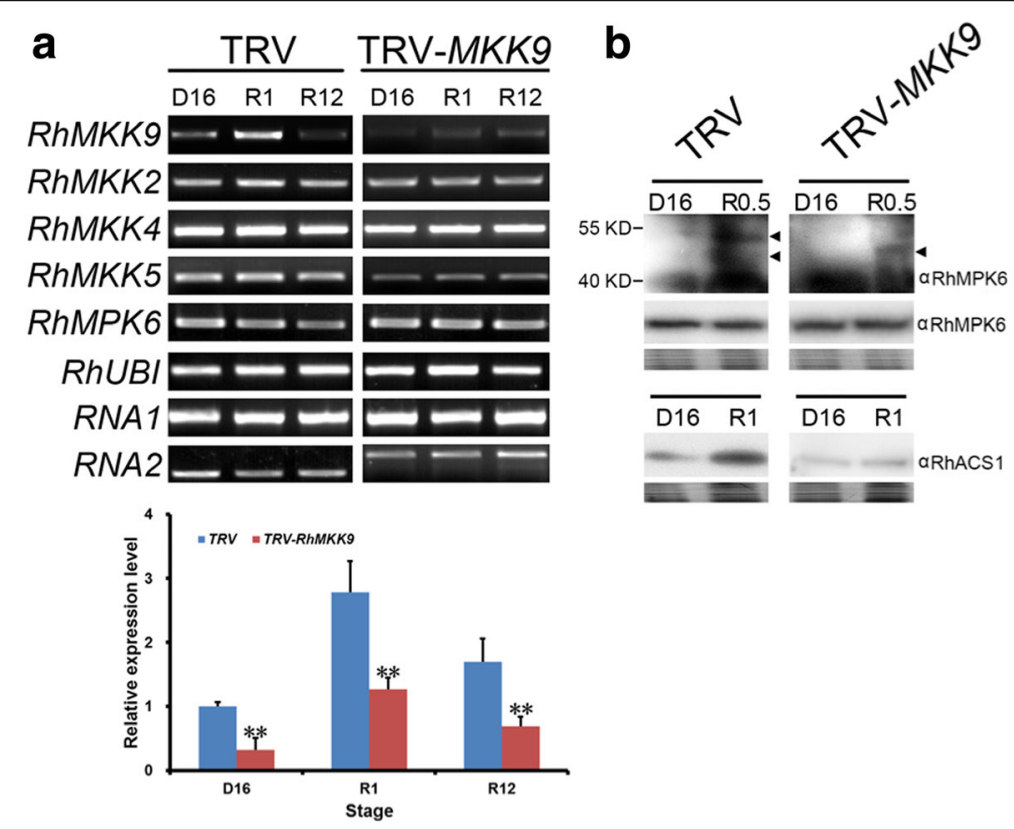

Fig. 3 Effects of RhMKK9 silencing in rose flowers. a Expression pattern of RhMKKs and RhMPK6. Upper panel, semi-quantitative RT-PCR assay of RhMKK9, RhMKK2, RhMKK4, RhMKK5, and RhMPK6 in TRV- and TRV-MKK9-infected flowers. RhUBI was used as an internal control. Bottom panel, quantification of RhMKK9 expression. At least three biological replicates were tested for each time point. Asterisks in the bottom panel indicated significant differences calculated using the $t$ test $\left({ }^{* *} p<0.01\right)$. b The RhMPK6 phosphorylation level and RhMPK6 and RhACS1 protein levels in TRV- and TRV-MKK9-infected flowers. The RhMPK6 phosphorylation level was monitored using the Phos-tag reagent. A Coomassie Brilliant Blue-stained blot is shown below to confirm equivalent sample loading. D16, dehydration for $16 \mathrm{~h}$; R0.5, R1, and R12, rehydration for 0.5 , 1, and $12 \mathrm{~h}$, respectively 
low level of RhMPK6 activity caused low level of RhACS1 protein and consequentially low ethylene production in $R h M K K 9$-silenced flowers during rehydration. Interestingly, we also detected a weak level of RhMPK6 kinase activity in RhMKK9-silenced lines. This could be attributed to the activity of residual RhMKK9 kinase because the $R h M K K 9$-silenced lines were knock-down instead of knock-out lines. These results confirmed that RhMKK 9 functioned upstream from RhMPK6 during rehydration.

Next, we compared the morphological changes of RhMKK9-silenced flowers with the TRV controls. On the first day after rehydration, petal loosening of the inner whorls of the TRV control was more obvious than that in the $R h M K K 9$-silenced flowers, implying that RhMKK9 silencing delayed the flower opening process. On the third day after rehydration, petals of the TRV2 flowers, especially in the inner whorl, faded to a bluish colour and the petals tended to droop in side view, indicating the flowers entered the phase of senescence (Fig. 4a, bottom panel) [23-25]. However, suppression of RhMKK9 expression obviously inhibited the petal bluing and drooping, implying that petal senescence was delayed (Fig. 4a, top panel). We also detected ethylene production in gynoecia of the TRV control and RhMKK9silenced flowers, respectively, during the dehydration and rehydration process. Similarly to the untreated flowers, ethylene production was triggered rapidly by rehydration in gynoecia of TRV control flowers [16] (Fig. 4b). However, silencing of $R h M K K 9$ significantly decreased the rehydration-induced ethylene production in gynoecia, indicating that $R h M K K 9$ was required for the rehydrationcaused increase of ethylene production in gynoecia (Fig. 4b).

\section{Silencing of RhMKK9 downregulated the expression of genes associated with senescence and induced by ethylene in petals}

Previous reports showed that rehydration-caused ethylene production in rose gynoecia could accelerate petal senescence by regulating the expression of genes downstream to ethylene signalling [7]. To obtain further insights into RhMKK9-silencing-delayed petal senescence, we monitored the expression of four genes in petals of TRV control and RhMKK9-silenced flowers during dehydration and rehydration. These four tested genes were all ethyleneinduced and included two transcription factor genes involving abiotic response and senescence, RhWRKY4O and $R h M Y B 108$ [22], a senescence-associated marker gene RhSAG12 [26], as well as an unknown gene, which was highly induced by ethylene [22]. We found that the expression of these four genes was significantly reduced in petals of RhMKK9-silenced flowers in the first hour of rehydration than those of the TRV controls (Fig. 5). During the twelfth hour after rehydration, RhWRKY4O and

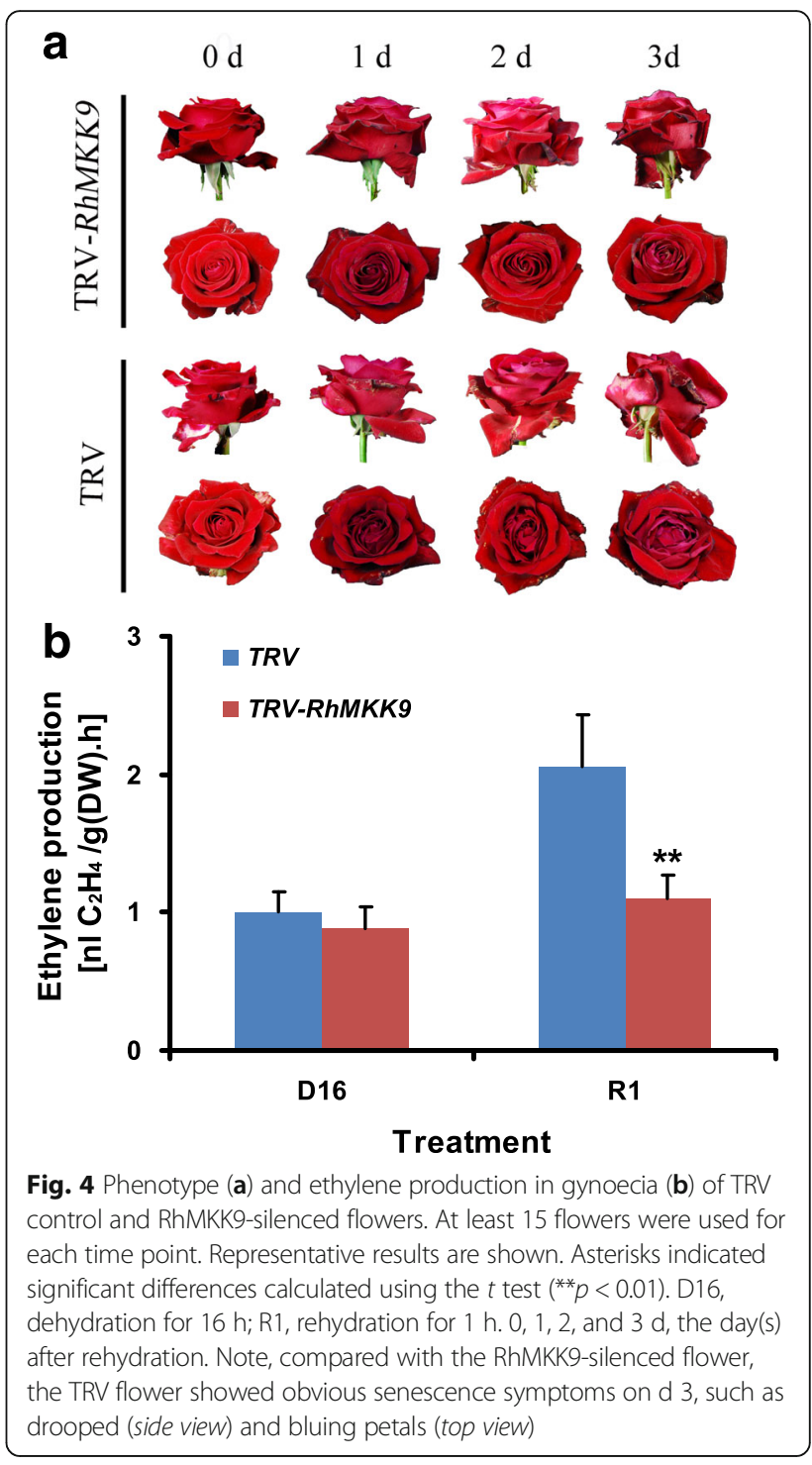

RhMYB108 expression in TRV control flowers was decreased to a relatively low level, which was similar to that of RhMKK9-silenced flowers, possibly owing to the low ethylene production level at this time (Fig. 5). However, RhSAG12 expression was still significantly higher in TRV controls than in $R h M K K 9$-silenced flowers, indicating that the senescence process of TRV control petals might be accelerated. These results implied that rehydration-caused ethylene production, which was a required action of RhMKK9, promoted the transcript accumulation of genes related to petal senescence and resulted in earlier petal senescence.

\section{DNA methylation status of the $R h M K K 9$ promoter and gene body is altered during rehydration}

Epigenetic modification has been reported to regulate multiple tolerances of plants to environmental stresses, 

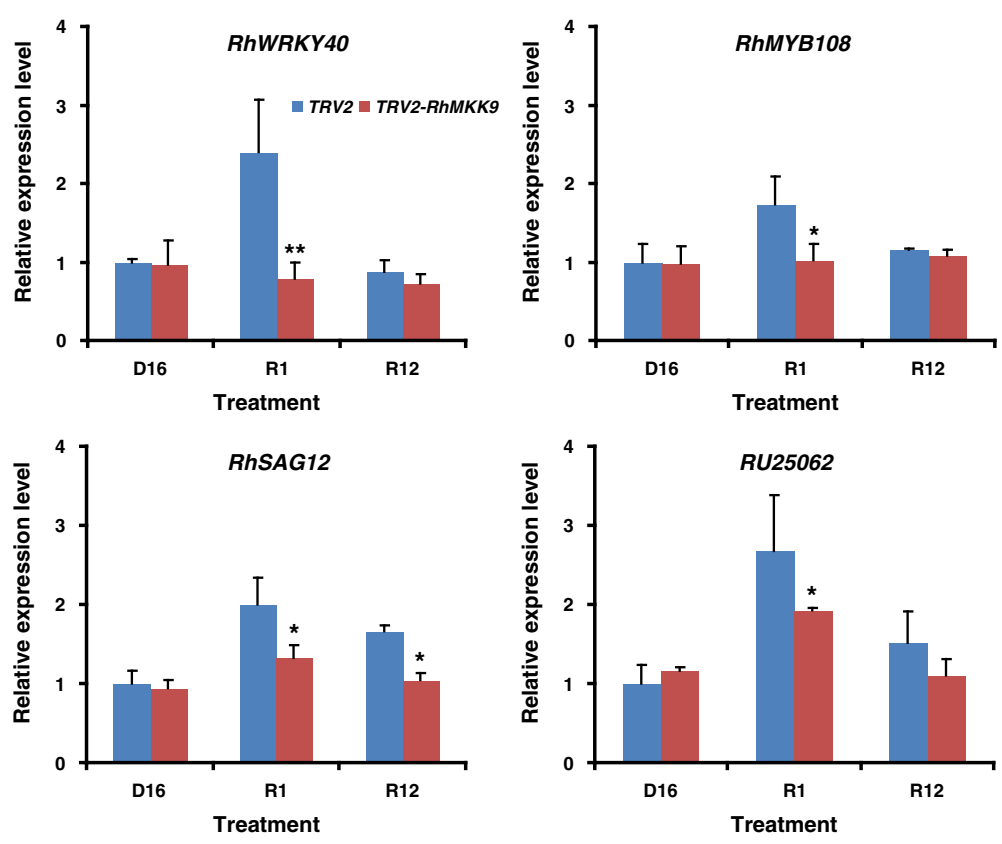

Fig. 5 Expression patterns of four ethylene-responsive genes in petals of TRV control and RhMKK9-silenced flowers. At least three biological replicates were tested for each time point. Asterisks in the bottom panel indicate significant differences calculated using the $t$ test $\left({ }^{* *} p<0.01,{ }^{*} p<0.05\right)$. D16, dehydration for $16 \mathrm{~h}$; R1 and R12, rehydration for $1 \mathrm{~h}$ and $12 \mathrm{~h}$, respectively

including heat stress, cold, and dehydration [27-30]. Recently, a report showed that histone modification was associated with inactivation of dehydration-inducible genes by rehydration in Arabidopsis [6]. Here, we tested the DNA methylation status of the RhMKK9 promoter and gene body by DNA methylation sensitive Chop-PCR. Five pairs of primers were designed to cover the $\sim 500 \mathrm{bp}$ upstream region to RhMKK9 ORF and gene body (Fig. 6a, Additional file 1: Figure S2). DNA methylation-specific $M c r B C$ digestion showed that the $\mathrm{F} 1+\mathrm{R} 1$ region was

\section{a}
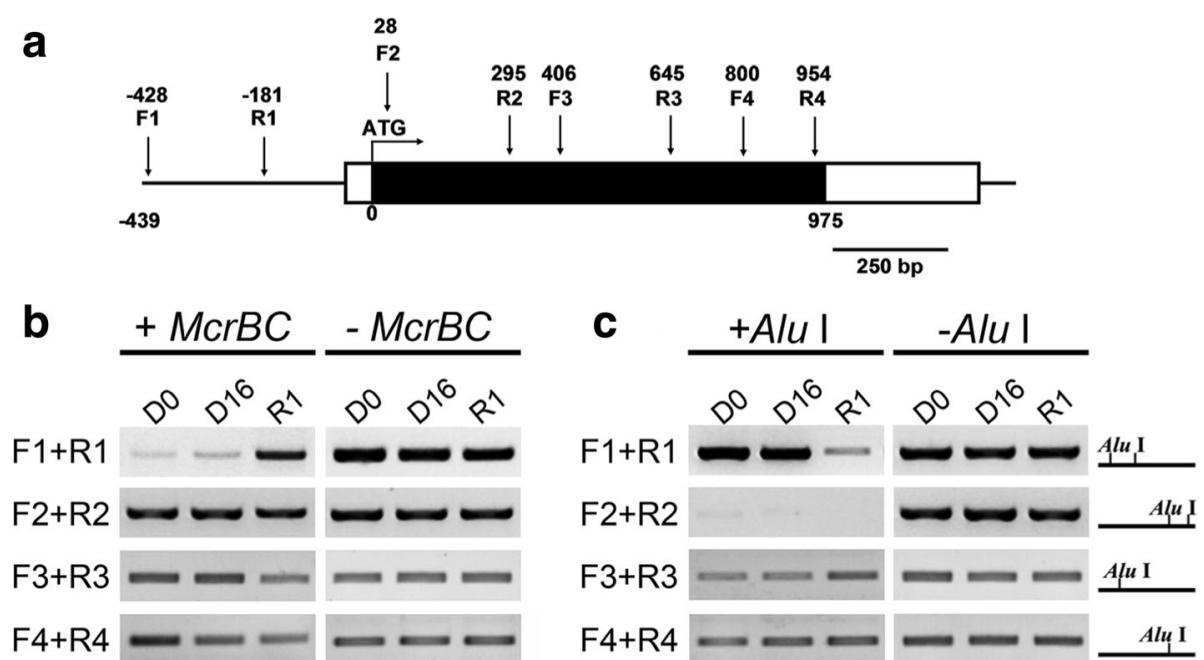

Fig. 6 Effects of dehydration and rehydration on DNA methylation of the RhMKK9 gene. The effects of dehydration and rehydration on cytosine DNA methylation in RhMKK9 gene (a) were determined by MCrBC digestion (b) and Alu I-mediated (c) Chop-PCR assays. a Schematic structure of RhMKK9 gene. The primers used for the Chop-PCR assay are indicated as F1 + R1, F2 + R2, F3 + R3, F4 + R4, and F5 + R5. b McrBC digestion assay. Genomic DNA was digested with McrBC for 3 h and amplified by PCR. c Alu I-mediated Chop-PCR assay. Linearised genomic DNA was digested with Alu I for $3 \mathrm{~h}$, respectively, and then was amplified by PCR. The right panel indicates the Alu I site in each tested region. In each assay, undigested genomic DNA was used as a control. Primers were listed in Additional file 1: Table S2. D0 and D16, dehydration for $0 \mathrm{~h}$ and $16 \mathrm{~h}$, respectively; R1, rehydration for $1 \mathrm{~h}$. Note, there is no intron in RhMKKG 
heavily methylated during dehydration, whereas they were de-methylated when the flowers were subjected to rehydration (Fig. 6b). However, the DNA methylation level of RhMKK9 ORF, including the F2 + R2, F3 + R3, and F4 + R4 regions, was slightly elevated during rehydration (Fig. 6b). DNA methylation was further tested by digestion with $A l u \mathrm{I}$. The results further supported that the F1 + R1 region of the $R h M K K 9$ promoter was hypomethylated, whereas the $R h M K K 9$ gene body was hypermethylated during rehydration (Fig. 6c). In general, DNA methylation on the promoter region was considered to play an inhibitory role in gene transcription, whereas DNA methylation on the gene body indicated the activation of gene expression [31, 32]. Thus, the results of the DNA methylation assay further supported the gene expression analysis of RhMKK9 during dehydration and rehydration, revealing that the induction of $R h M K K 9$ expression by rehydration might result from rehydration-caused DNA demethylation in the $R h M K K 9$ promoter.

\section{Discussion}

Despite its simple structure, ethylene is functionally complex and plays a crucial role in a broad spectrum of plant developmental and environmental responses [33, 34]. Ethylene acts as an essential mediator in post-pollination fertilisation and ovule development, as well as associated petal senescence in various plants [35-39]. In Arabidopsis, ethylene was reported to be indispensable for fertilisation by inducing synergid cell death and establishing pollen tube block [39]. In Phalaenopsis, a pollination-induced ethylene burst in the stigma and style ensured appropriate ovary development, and considerably promoted perianth senescence [35, 37]. Similarly, in carnation (Dianthus caryophyllus) flowers, removal of gynoecia repressed the production of ethylene and delayed petal senescence [40].

Among the various abiotic stresses, dehydration is known to influence ethylene production in plants, although the underlying regulatory mechanism seems complex. In plants such as cotton (Gossypium hirsutum L.) petioles and bolls [41, 42], wheat (Triticum aestivum L.) leaves [43], orange (Citrus sinensis Osbeck) flowers [44], as well as persimmon (Diospyros kaki Thunb.), and avocado (Persea americana Mill.) fruit, dehydration induces ethylene production $[45,46]$. In detached persimmon fruit, water-loss induced ethylene burst in the calyx triggered ethylene production in other tissues and accelerated fruit ripening and softening [46].

In rose flowers, dehydration gradually increased ethylene production in sepals, whereas rehydration following a period of dehydration triggered rapid ethylene production in gynoecia [7]. Moreover, the ethylene production in gynoecia, although very transient, is essential for the flower to fully open, suggesting that ethylene is naturally required for the water recovery of dehydrated flowers
[16]. Considering that continuous ethylene production is very harmful to flowers, the timing of ethylene production should be tightly regulated. Biochemical analysis demonstrated that protein phosphorylation-dependent accumulation of RhACS1, a rate-limiting enzyme of ethylene biosynthesis, is responsible for controlling the timing of ethylene production. In addition, RhACS1 protein phosphorylation is attributed to RhMPK6, a MAP kinase, which is also precisely regulated by rehydration in rose flowers [16]. More important, RhMPK6 abundance is retained at a relatively constant level during both dehydration and rehydration, whereas RhMPK6 activation only occurs within $1 \mathrm{~h}$ of rehydration. Thus, these results indicate that appropriate ethylene production is important for the natural recovery process of rose flowers during rehydration. Therefore, it is not necessary for constant RhMPK6 accumulation during dehydration and rehydration, which is an energy-consuming process. Moreover, because MAPKs must be activated by MAPK KINASEs, it is reasonable to speculate that an upstream component should be involved in the rehydrationactivation of RhMPK6.

In Arabidopsis, MPK6 has been reported to be activated by different MAPK kinases in response to various biotic and abiotic stresses [47, 48]. Cold and salinity stress caused activation of MPK6 is, at least partially, dependent on MKK2 [49, 50], whereas MKK5 is required for oxidative-triggered MPK6 [51, 52]. For drought stress, although MPK6 is activated by drought-induced ROS accumulation [53], the corresponding MAPK kinase has not been identified. Expression of the active version of MKK9 promotes MPK3 and MPK6 kinase activity and ethylene production, and enhances the sensitivity of transgenic Arabidopsis to salt stress [54].

Here, we isolated the homologues of $M K K 2, M K K 4$, $M K K 5$, and $M K K 9$ from roses and detected their expression during dehydration and rehydration. It is noteworthy that $R h M K K 9$ expression, which could phosphorylate RhMPK6 in vitro [16], was relatively lower during dehydration, but significantly and sharply induced at the onset of rehydration, and then rapidly decreased to similar level before rehydration. Furthermore, specific silencing of RhMKK9 led to a significant reduction of rehydrationinduced ethylene production in gynoecia. The rehydrationresponsive expression pattern and function identification suggested that $R h M K K 9$ is possibly the upstream component regulating the rehydration-activated RhMPK6RhACS1 cascade and ethylene production in rose gynoecia. Interestingly, RhMKK9 silencing delayed both flower opening and senescence, further supporting that rehydrationcaused ethylene production accelerated flower opening and senescence. Detection of gene expression showed that rehydration led to the rapid expression elevation of several ethylene-inducible genes, which were involved in abiotic 
stress-response and senescence, in TRV control flowers. Consistently, expression of ethylene-inducible genes was significantly inhibited in $R h M K K$-silenced flowers. It is worth noting that the expression of two transcription factor genes, RhWRKY40 and RhMYB108, decreased after $12 \mathrm{~h}$ of rehydration in TRV controls to a relatively low level, similarly to RhMKK9-silenced flowers. Therefore, RhWRKY4O and RhMYB108 might be closely associated with ethylene production. However, expression of the senescence-associated RhSAG12 gene in the TRV control was significantly higher than that in RhMKK9-silenced flowers at $12 \mathrm{~h}$ after rehydration, implying that rehydration-caused ethylene production might also initiate the petal senescence process.

In the last decade, increasing evidence has shown epigenetic modification plays crucial roles in tolerance, adaption, and memory of plants to various abiotic stresses [27-30]. In Arabidopsis, histone modification of H3K4me3 and H3K9ac were enriched in drought stress-induced genes $[6,30,55]$. In the rehydration process, $\mathrm{H} 3 \mathrm{~K} 9 \mathrm{ac}$ was rapidly removed, correlating to the inactivation of drought-inducible genes. Interestingly, H3K4me3 was removed more slowly than the H3K9ac mark, suggesting that H3K4me3 may be responsible for the epigenetic memory of drought $[6,30]$. In rice, drought stress induced gene expression of the histone acetyltransferase (HATs) family and enhanced acetylation of H3K9, H3K18, H3K27, and H4K5 [56].

Dynamic DNA methylation and demethylation has also been broadly reported to be involved in plant responses to abiotic stresses [57-61]. In maize, cold stress-induced ZmMI1 gene expression is associated with DNA hypomethylation in the nucleosome cores [62]. Here, we found that rehydration also resulted in hypomethylation on the $R h M K K 9$ promoter, whereas elevated methylation on the $R h M K K 9$ gene body. The factors involved in this rapid methylation and de-methylation process should be the subject of further studies.

\section{Conclusions}

In summary, a MAPK KINASE, RhMKK9, is the upstream component responsible for activating the RhMPK6RhACS1 cascade. RhMKK9 expression was specifically and rapidly induced by rehydration in gynoecia. RhMKK9 silencing inhibited rehydration-caused ethylene bursts and delayed flower opening and senescence. In addition, we found that changes of DNA methylation status on the RhMKK9 promoter and gene body were associated with $R h M K K 9$ induction by rehydration. These results explained how the flower, the reproductive organ, could quickly recover from dehydration using ethylene as a mediator.

\section{Methods}

\section{Plant materials}

Flowers of $R$. hybrida 'Samantha' were provided by a commercial greenhouse (Sunstone Company) in the Changping District, Beijing. The flowers were harvested at opening stage 2 as described previously [18]. The flowers were immediately placed in tap water and transported to the laboratory within $1 \mathrm{~h}$. Stems of the rose flowers were re-cut underwater to approximately $25 \mathrm{~cm}$, and then were kept in deionised water (DW) until further processing.

\section{Dehydration and rehydration treatments}

Dehydration treatment was conducted as described previously $[7,16]$. Flowers were placed horizontally on the bench in a climate-controlled room at $25{ }^{\circ} \mathrm{C}, 40-50 \%$ relative humidity, and a continuous light with intensity of $140 \mu \mathrm{mol} \mathrm{m} \mathrm{m}^{-2} \mathrm{~s}^{-1}$. The dehydration status was defined by fresh weight loss, and the flowers were subjected to rehydration when the flowers lost $\sim 30 \%$ fresh weight. After the dehydration treatment, the bottom of flower stems were re-cut to remove about $1 \mathrm{~cm}$ under water to prevent air embolisms, and the flowers were placed in deionised water for rehydration. The flower phenotype was observed at different time points: $0,1,2$, and $3 \mathrm{~d}$ after rehydration. After treatment, the flowers were cut open and the gynoecia, including carpels and pistils, were sampled as described previously $[7,16,20]$. Half of the gynoecia at D16 (dehydration for $16 \mathrm{~h}$ ) and R1 (rehydration for $1 \mathrm{~h}$ ) were taken for the ethylene production test, whereas the petals and the other half of the gynoecia were collected and frozen using liquid nitrogen and then were stored at $-80^{\circ} \mathrm{C}$ for RNA isolation.

\section{Ethylene production measurement}

The gynoecia were weighed and then placed in a $25 \mathrm{ml}$ airtight GC vial, and the vials were kept for $30 \mathrm{~min}$ at $25^{\circ} \mathrm{C}$. From each vial, $2 \mu \mathrm{l}$ headspace gas was withdrawn to measure ethylene concentration using a gas chromatograph equipped with a flame ionisation detector (GC-17A, Shimadzu, Japan) as described previously [7, 20]. After ethylene measurement, the gynoecia were dried in an oven at $60{ }^{\circ} \mathrm{C}$ to determine their dry weight, and then the ethylene production was calculated. Fifteen flowers were used for each time point.

\section{Sequence analysis}

Alignment of multiple deduced amino acid sequences was constructed using ClustalW2 software and visualised using the BioEdit program. Phylogenetic analysis was performed using MEGA 5.2. 
RNA extraction, semi-quantitative RT-PCR analyses

Total RNA of petals was isolated using the hot borate method as described previously [19], and the total RNA of gynoecia was extracted using a RN38-EASY RNA extraction kit (Aidlab, Co, Ltd., Beijing, PRC). Total RNA was treated by RNase-free DNase I to avoid genomic DNA contamination. An volume of $1 \mu \mathrm{g}$ of clean RNA was used to synthesise cDNA using M-MLV reverse transcriptase (Promega Corp., Madison, WI, USA) according to the manufacturer's instructions. The rose ubiquitin gene (RhUBI, JK622648) was used as the internal control. The primers used in the RT-PCR analysis are listed in Additional file 1: Table S2. PCR reactions were carried out for $5 \mathrm{~min}$ at $94{ }^{\circ} \mathrm{C}$, followed by 30 cycles of $30 \mathrm{~s}$ at $94{ }^{\circ} \mathrm{C}, 30 \mathrm{~s}$ at $58{ }^{\circ} \mathrm{C}, 30 \mathrm{~s}$ at $72{ }^{\circ} \mathrm{C}$, and followed by a supplemental incubation for $7 \mathrm{~min}$ at $72{ }^{\circ} \mathrm{C}$ for all the genes. The PCR products were separated on $1.5 \%$ agarose gels and visualised by ethidium bromide staining. Absolute values for transcript abundance from RT-PCR were quantified using the Alpha EaseFCTM 2200 software (Alpha Innotech, USA, Version 3.2.1). For all experiments, an individual flower was considered as a biological replicate and all experiments were performed with at least three replicates.

RhMKK9 gene silencing was performed as previously described [19]. A 490-bp fragment from the RhMKK9specific 3' end (partial ORF and entire 3'UTR) was used to construct pTRV2-RhMKK9. The resulting constructs pTRV2-RhMKK9, pTRV1, and pTRV2 were transformed into Agrobacterium tumefaciens strain GV3101. Briefly, Agrobacterium was grown in LB broth containing $50 \mu \mathrm{g} \mathrm{ml} l^{-1}$ kanamycin and $50 \mu \mathrm{g} \mathrm{ml}^{-1}$ gentamycin sulphate at $28{ }^{\circ} \mathrm{C}$ with shaking at $200 \mathrm{rpm}$ overnight. These cultures were then diluted 1:50 v/v in fresh LB broth containing $10 \mathrm{mM}$ MES, $20 \mathrm{mM}$ acetosyringone, $50 \mu \mathrm{g} \mathrm{ml}{ }^{-1}$ kanamycin, and $50 \mu \mathrm{g} \mathrm{ml}{ }^{-1}$ gentamycin sulphate, and grown overnight as described above. Agrobacterium cells were harvested by centrifugation, and the pellet was suspended in infiltration buffer (10 $\mathrm{mM} \mathrm{MgCl} 2,150 \mathrm{mM}$ acetosyringone, and $10 \mathrm{mM}$ MES, pH 5.6) to a final A600 of 1.8. A mixture of Agrobacterium cultures containing pTRV1 and pTRV2RhMKK9 at a ratio of $1: 1(\mathrm{v} / \mathrm{v})$ was used for rose transformation, and a mixture containing pTRV1 and pTRV2 was used as the negative control. The mixtures were stored at room temperature for $4 \mathrm{~h}$ in the dark prior to vacuum infiltration.

For vacuum infiltration, the flowers were placed upside down in a container $(81.64 \mathrm{~L})$, with the whole flower immersed into the prepared infiltration mixture. The flowers were then infiltrated by vacuum at $30 \mathrm{mmHg}$ twice, each for $2 \mathrm{~min}$. Then they were briefly washed with DW and kept in DW for $3 \mathrm{~d}$ at $8{ }^{\circ} \mathrm{C}$ before the dehydration treatment [16].

\section{Immunoblot and kinase activity assays}

Gynoecia protein was extracted as described previously [63]. The following antibodies were used: goat polyclonal IgG anti-ACC synthase 6 antibody (SC-12771, Santa Cruz Biotechnology, http://www.scbt.com) to detect RhACS1; polyclonal anti-MPK6 (Sigma-Aldrich, http:// www.sigmaaldrich.com) to detect RhMPK6. Secondary antibodies (horseradish peroxidase-conjugated goat antimouse IgG, Sigma-Aldrich) were used as recommended in the manufacturer's instructions.

For the kinase activity assay, SDS-PAGE gel was supplied with $25 \mu \mathrm{M}$ Phos-tag (Wako Chemicals) and $50 \mu \mathrm{M} \mathrm{Zn}^{+}$was used as described previously [64-66]. The running buffer contained $100 \mathrm{mM}$ Tris, $100 \mathrm{mM}$ MOPS, and $0.1 \%(\mathrm{w} / \mathrm{v})$ SDS. Sodium bisulphite was added to $5 \mathrm{mM}$ immediately before electrophoresis.

\section{DNA methylation assay}

DNA methylation status was analysed by Chop-PCR as described previously [67]. For Chop-PCR, genomic DNA (500 ng) was digested with the methylation-sensitive restriction enzyme Alu I, or by the methylated DNAdigesting enzyme $M c r B C$ for $3 \mathrm{~h}$. The digested DNA was used as a template to amplify the $R h M K K 9$ promoter and gene body. Undigested genomic DNA was amplified as an internal control.

\section{Additional file}

Additional file 1: Figure S1. Alignment analysis of RhMKK2 (A), RhMKK4 (B), and RhMKK5 (C). The proteins used include, RhMKK2, rose (Rose hybrida), ALG02503.1; FvMKK2, woodland strawberry (Fragaria vesca subsp. vesca), XP_011460401.1; MdMKK2, apple (Malus domestica), XP_008337740.1; PbMKK2, Chinese white pear (Pyrus $x$ bretschneideri), XP_009361655.1; PmMKK2, Chinese plum (Prunus mume), XP_008242181.1; EgMKK2, rose gum (Eucalyptus grandis), XP_010047526.1; RhMKK4, rose (R. hybrida), ALG02504.1; MdMKK5, apple (M. domestica), XP_008380261.1; FvMKK5, woodland strawberry (F. vesca subsp. vesca), XP_004303847.1; PbMKK5, Chinese white pear (P. x bretschneideri), XP_009333993.1; PmMKK5, Chinese plum (Prunus mume),

XP_008229371.1; PtMKK4, black cottonwood (Populus trichocarpa); RhMKK5, rose (R. hybrida), XP 006379405.1; ALG02505.1. Table S1. Gene information of rose MAP KINASE KINASE. Table S2. Oligonucleotide primer sequences. (DOC $384 \mathrm{~kb}$ )

\section{Abbreviations}

ACS: 1-aminocyclopropane-1-carboxylic acid synthase; MAPK: Mitogenactivated protein kinase; MAPKKK: Mitogen-activated protein kinase kinase kinase; MKK: Mitogen-activated protein kinase kinase; ORF: Open reading frame; SAG: Senescence-associated gene; TRV: Tobacco rattle virus; UTR: Untranslated region; VIGS: Virus-induced gene silencing

\section{Acknowledgements}

We thank Dr Pedro Nunes from Shanghai Center for Plant Stress Biology for his technical advice in Chop-PCR and excellent suggestions in writing.

\section{Funding}

This work was supported by the National Natural Science Foundation of China, (Grant 31130048 and 31372095), and the 948 project (2011-G17) of the Ministry of Agriculture of China. 


\section{Availability of data and materials}

All data supporting the findings is contained within the manuscript and supplemental data sections. The complete coding sequences of RhMKK2, RhMKK4, RhMKK5, and RhMKK9 is available at NCBI under accession numbers KP269070, KP269071, KP269072, and KP269073, respectively.

\section{Authors' contributions}

NM and JG conceived and designed the study. JC and QZ performed phenotypic analysis, and VIGS, QW, and YM performed the gene expression analyses. MF, YL, and ZM performed immunoblot analyses of RhMPK6 and RhACS1, and the phosphorylation assay of RhMPK6. YZ and GL performed the experiments of Chop-PCR. HW was also involved in gene expression analysis. All authors have read and approved the final manuscript.

\section{Competing interests}

The authors declare that they have no competing interests.

\section{Consent for publication}

Not applicable.

\section{Ethics approval and consent to participate}

Not applicable.

\section{Author details}

'Department of Ornamental Horticulture, China Agricultural University, Beijing 100193, China. ${ }^{2}$ Beijing Key Laboratory of Development and Quality Control of Ornamental Crops, China Agricultural University, No. 2 Yuanmingyuan West Road, Haidian District, Beijing 100193, China. ${ }^{3}$ Flower Research Institute, Yunnan Academy of Agricultural Sciences, Kunming 650205, China. ${ }^{4}$ College of Biology and Environmental Engineering, Provincial Key Laboratory of Biocontrol, Guiyang University, Guiyang 550005, China. ${ }^{5}$ College of Horticulture and Landscape, University, Yunnan Agricultural University, Kunming 650201, China.

\section{Received: 29 January 2016 Accepted: 9 February 2017}

Published online: 23 February 2017

\section{References}

1. Šamajová O, Komis G, Šamaj J. Emerging topics in the cell biology of mitogen-activated protein kinases. Trends Plant Sci. 2013;18:140-8.

2. Šamajová O, Plíhal O, Al-Yousif M, Hirt H, Šamaj J. Improvement of stress tolerance in plants by genetic manipulation of mitogen-activated protein kinases. Biotechnol Adv. 2013;31:118-28.

3. Shinozaki K, Yamaguchi-Shinozaki K. Molecular responses to dehydration and low temperature: differences and cross-talk between two stress signaling pathways. Curr Opin Plant Biol. 2000;3:217-23.

4. Zhu JK. Salt and drought stress signal transduction in plants. Annu Rev Plant Physiol Plant Mol Biol. 2002;53:247-73.

5. Oono Y, Seki M, Nanjo T, Narusaka M, Fujita M, Satoh R, Satou M, Sakurai T, Ishida J, Akiyama K, lida K, Maruyama K, Satoh S, Yamaguchi-Shinozaki K, Shinozaki K. Monitoring expression profiles of Arabidopsis gene expression during rehydration process after dehydration using ca. 7000 full-length cDNA microarray. Plant J. 2003;34:868-87.

6. Kim JM, To TK, Ishida J, Matsui A, Kimura H, Seki M. Transition of chromatin status during the process of recovery from drought stress in Arabidopsis thaliana. Plant Cell Physiol. 2012;53:847-56.

7. Liu D, Liu X, Meng Y, Sun C, Tang H, Jiang Y, Khan MA, Xue J, Ma N, Gao J. An organ-specific role for ethylene in rose petal expansion during dehydration and rehydration. J Exp Bot. 2013;64:2333-44.

8. Colcombet J, Hirt H. Arabidopsis MAPKs: a complex signalling network involved in multiple biological processes. Biochem J. 2008:413:217-26.

9. Rodríguez-Peña JM, García R, Nombela C, Arroyo J. The high-osmolarity glycerol (HOG) and cell wall integrity (CWI) signalling pathways interplay: a yeast dialogue between MAPK routes. Yeast. 2010;27:495-502.

10. Hahn A, Harter K. Mitogen-activated protein kinase cascades and ethylene: signaling, biosynthesis, or both? Plant Physiol. 2009;149:1207-10.

11. Šamajová O, Komis G, Šamaj J. Immunofluorescent localization of MAPKs and colocalization with microtubules in Arabidopsis seedling whole-mount probes. In: Plant MAP Kinases. New York: Springer; 2014. p. 107-15.
12. Keshet $Y$, Seger R. The MAP kinase signaling cascades: a system of hundreds of components regulates a diverse array of physiological functions. In MAP Kinase Signaling Protocols. New York city, USA: Humana Press; 2010. p. 3-38.

13. Ichimura K, Mizoguchi T, Yoshida R, Yuasa T, Shinozaki K. Various abiotic stresses rapidly activate Arabidopsis MAP kinases ATMPK4 and ATMPK6. Plant J. 2000;24:655-65.

14. Xu J, Chua NH. Dehydration stress activates Arabidopsis MPK6 to signal DCP1 phosphorylation. EMBO J. 2012;31:1975-84.

15. Tsugama D, Liu S, Takano T. Drought-induced activation and rehydrationinduced inactivation of MPK6 in Arabidopsis. Biochem Biophy Res Commun. 2012:426:626-9.

16. Meng Y, Ma N, Zhang Q, You Q, Li N, Khan MA, Liu XJ, Wu L, Su Z, Gao J. Precise spatio-temporal modulation of ACC synthase by MPK6 cascade mediates the response of rose flowers to rehydration. Plant J. 2014;79:941-50.

17. Reid MS, Evans RY, Dodge LL, Mor Y. Ethylene and silver thiosulphate influence opening of cut rose flowers. J Am Soc Hortic Sci. 1989;114:436-40.

18. Ma N, Cai L, Lu W, Tan H, Gao J. Exogenous ethylene influences flower opening of cut roses (Rosa hybrida) by regulating the genes encoding ethylene biosynthesis enzymes. Sci China C Life Sci. 2005;48:434-44.

19. Ma N, Xue JQ, Li YH, Liu XJ, Dai FW, Jia WS, Luo YB, Gao JP. Rh-PIP2;1, a rose aquaporin gene, is involved in ethylene-regulated petal expansion. Plant Physiol. 2008;148:894-907.

20. Xue JQ, Li YH, Tan H, Yang F, Ma N, Gao JP. Expression of ethylene biosynthetic and receptor genes in rose floral tissues during ethyleneenhanced flower opening. J Exp Bot. 2008:59:2161-9.

21. Andreasson E, Ellis B. Convergence and specificity in the Arabidopsis MAPK nexus. Trends Plant Sci. 2010;15:106-13.

22. Pei HX, Ma N, Chen JW, Zheng Y, Tian J, Li J, Zhang S, Fei ZJ, Gao JP. An NAC transcription factor controls ethylene-regulated cell expansion in flower petals. Plant Physiol. 2013;163:775-91.

23. Itzhaki H, Borochov A, Mayak S. Age-related-changes in petal membranes from attached and detached rose flowers. Plant Physiol. 1990;94:1233-6.

24. Ma N, Tan H, Liu XJ, Xue JQ, Li YH, Gao JP. Transcriptional regulation of ethylene receptor and CTR genes involved in ethylene-induced flower opening in cut rose (Rosa hybrida) cv. Samantha. J Exp Bot. 2006;57:2763-73.

25. Schmitzer V, Veberic R, Osterc G, Stampar F. Color and phenolic content changes during flower development in groundcover rose. J Am Soc Hortic Sci. 2010;135:195-202.

26. Lü P, Zhang C, Liu J, Liu X, Jiang G, Jiang X, Khan MA, Wang LS, Hong B, Gao JP. RhHB1 mediates the antagonism of gibberellins to ABA and ethylene during rose (Rosa hybrida) petal senescence. Plant J. 2014;78:578-90.

27. Chinnusamy V, Zhu JK. Epigenetic regulation of stress responses in plants. Curr Opin Plant Biol. 2009;12:133-9.

28. Hirayama T, Shinozaki K. Research on plant abiotic stress responses in the post-genome era: past, present and future. Plant J. 2010;61:1041-52.

29. Chinnusamy V, Dalal M, Zhu JK. Epigenetic regulation of abiotic stress responses in plants. Plant Abiotic Stress 2nd Ed. 2014; p. 203-229.

30. Kim J, Sasaki T, Ueda M, Sako K, Seki M. Chromatin changes in response to drought, salinity, heat, and cold stresses in plants. Front Plant Sci. 2015;6:114.

31. Suzuki M, Bird A. DNA methylation landscapes: provocative insights from epigenomics. Nat Rev Genet. 2008;9:465-76.

32. Jones PA. Functions of DNA methylation: islands, start sites, gene bodies and beyond. Nat Rev Genet. 2012;13:484-92.

33. Abeles FB, Morgan PW, Saltveit Jr ME. Ethylene in Plant Biol. Massachusetts, USA: Academic Press; 1992

34. Bleecker AB, Kende H. Ethylene: a gaseous signal molecule in plants. Annu Rev Cell Dev Biol. 2000;16:1-40.

35. Zhang XS, O'Neill SD. Ovary and gametophyte development are coordinately regulated by auxin and ethylene following pollination. Plant Cell. 1993;5:403-18.

36. Wang $\mathrm{H}$, Wu HM, Cheung AY. Pollination induces mRNA poly (A) tail-shortening and cell deterioration in flower transmitting tissue. Plant J. 1996;9:715-27.

37. Bui AQ, O'Neill SD. Three 1-aminocyclopropane-1-carboxylate synthase genes regulated by primary and secondary pollination signals in orchid flowers. Plant Physiol. 1998;116:419-28.

38. De Martinis D, Mariani C. Silencing gene expression of the ethyleneforming enzyme results in a reversible inhibition of ovule development in transgenic tobacco plants. Plant Cell. 1999;11:1061-71.

39. Völz R, Heydlauff J, Ripper D, von Lyncker L, Groß-Hardt R. Ethylene signaling is required for synergid degeneration and the establishment of a pollen tube block. Dev Cell. 2013;25:310-6. 
40. Shibuya K, Yoshioka T, Hashiba T, Satoh S. Role of the gynoecium in natural senescence of carnation (Dianthus caryophyllus L.) flowers. J Exp Bot. 2000; 51:2067-73.

41. Guinn G. Water deficit and ethylene evolution by young cotton bolls. Plant Physiol. 1976;57:403-5

42. Mcmichael $B L$, Jordan WR, Powell RD. An effect of water stress on ethylene production by intact cotton petioles. Plant Physiol. 1972;49:658-60.

43. Mckeon TA, Hoffman NE, Yang SF. Effect of plant hormone pretreatments on ethylene production and synthesis of 1-aminocyclopropane--carboxylic acid in water stressed wheat leaves. Planta. 1982;155:437-43.

44. Ben-Yehoshua S, Aloni B. Effect of water stress on ethylene production by detached leaves of Valencia orange (Citrus sinensis Osbeck). Plant Physiol. 1974;53:863-5.

45. Adato I, Gazit S. Water-deficit, ethylene production, and ripening in avocado fruits. Plant Physiol. 1974;53:45-6.

46. Nakano R, Ogura E, Kubo Y, Inaba A. Ethylene biosynthesis in detached young persimmon fruit is initiated in calyx and modulated by water loss from the fruit. Plant Physiol. 2003;131:276-86.

47. Lee JS, Huh KW, Bhargava A, Ellis BE. Comprehensive analysis of proteinprotein interactions between Arabidopsis MAPKs and MAPK kinases helps define potential MAPK signalling modules. Plant Signal Behav. 2008;3:1037-41.

48. Smékalová V, Doskočilová A, Komis G, Šamaj J. Crosstalk between secondary messengers, hormones and MAPK modules during abiotic stress signalling in plants. Biotechnol Adv. 2014;32:2-11.

49. Pitzschke A, Schikora A, Hirt H. MAPK cascade signalling networks in plant defence. Curr Opin Plant Biol. 2009;12:421-6.

50. Teige M, Scheikl E, Eulgem T, Dóczi R, Ichimura K, Shinozaki K, Dangl JL, Hirt $\mathrm{H}$. The MKK2 pathway mediates cold and salt stress signaling in Arabidopsis. Mol Cell. 2004:15:141-52

51. Miles GP, Samuel MA, Ellis BE. Suppression of MKK5 reduces ozone-induced signal transmission to both MPK3 and MPK6 and confers increased ozone sensitivity in Arabidopsis thaliana. Plant Signal Behav. 2009;4:687-92.

52. Xing Y, Cao Q, Zhang Q, Qin L, Jia W, Zhang J. MKK5 regulates high lightinduced gene expression of $\mathrm{Cu} / \mathrm{Zn}$ superoxide dismutase 1 and 2 in Arabidopsis. Plant Cell Physiol. 2013;54:1217-27.

53. Yu L, Nie J, Cao C, Jin Y, Yan M, Wang F, Liu J, Xiao Y, Liang YH, Zhang W. Phosphatidic acid mediates salt stress response by regulation of MPK6 in Arabidopsis thaliana. New Phytol. 2010;188:762-73.

54. Xu J, Li Y, Wang Y, Liu H, Lei L, Yang H, Liu GQ, Ren D. Activation of MAPK kinase 9 induces ethylene and camalexin biosynthesis and enhances sensitivity to salt stress in Arabidopsis. J Biol Chem. 2008;283:26996-7006.

55. Kim JM, To TK, Ishida J, Morosawa T, Kawashima M, Matsui A, Toyoda T, Kimura $\mathrm{H}$, Shinozaki K, Seki M. Alterations of lysine modifications on the histone $\mathrm{H} 3 \mathrm{~N}$-tail under drought stress conditions in Arabidopsis thaliana. Plant Cell Physiol. 2008;49:1580-8.

56. Fang H, Liu X, Thorn G, Duan J, Tian L. Expression analysis of histone acetyltransferases in rice under drought stress. Biochem Biophy Res Commun. 2014:443:400-5.

57. Choi CS, Sano H. Abiotic-stress induces demethylation and transcriptional activation of a gene encoding a glycerophosphodiesterase-like protein in tobacco plants. Mol Genet Genomics. 2007;277:589-600.

58. Boyko A, Blevins T, Yao Y, Golubov A, Bilichak A, Inytskyy Y, Hollander J, Meins Jr F, Kovalchuk I. Transgenerational adaptation of Arabidopsis to stress requires DNA methylation and the function of Dicer-like proteins. PLoS One. 2010;5:e9514.

59. Bilichak A, Inystkyy Y, Hollunder J, Kovalchuk I. The progeny of Arabidopsis thaliana plants exposed to salt exhibit changes in DNA methylation, histone modifications and gene expression. PLoS One. 2012;7:e30515.

60. Karan R, Deleon T, Biradar H, Subudhi PK. Salt stress induced variation in DNA methylation pattern and its influence on gene expression in contrasting rice genotypes. PLoS One. 2012;7:e40203.

61. Wang M, Qin L, Xie C, Li W, Yuan J, Kong L, Yu W, Xia G, Liu S. Induced and constitutive DNA methylation in a salinity-tolerant wheat introgression line. Plant Cell Physiol. 2014;55:1354-65.

62. Steward N, Ito M, Yamaguchi Y, Koizumi N, Sano H. Periodic DNA methylation in maize nucleosomes and demethylation by environmental stress. J Biol Chem. 2002;277:37741-6.

63. Romeis T, Ludwig AA, Martin R, Jones JD. Calcium-dependent protein kinases play an essential role in a plant defence response. EMBO J. 2001;20:5556-67.
64. Meng X, Xu J, He Y, Yang KY, Mordorski B, Liu Y, Zhang S. Phosphorylation of an ERF transcription factor by Arabidopsis MPK3/MPK6 regulates plant defense gene induction and fungal resistance. Plant Cell. 2013;25:1126-42.

65. Kang S, Yang F, Li L, Chen H, Chen S, Zhang J. The Arabidopsis transcription factor BRASSINOSTEROID INSENSITIVE1-ETHYL METHANE -SULFONATESUPPRESSOR1 is a direct substrate of MITOGEN-ACTIVATED PROTEIN KINASE6 and regulates immunity. Plant Physiol. 2015;167:1076-86.

66. Bekešová $S$, Komis $G$, Křenek $P$, Vyplelova $P$, Ovečka $M$, Luptovčiak I, Ilés $P$, Kuchařová A, Šamaj J. Monitoring protein phosphorylation by acrylamide pendant Phos-Tag ${ }^{\text {TM }}$ in various plants. Front Plant Sci. 2015;6:336.

67. Zhang H, Tang K, Wang B, Duan C-G, Lang Z, Zhu J-K. Protocol: a beginner's guide to the analysis of RNA-directed DNA methylation in plants. Plant Methods. 2014;10:18.

\section{Submit your next manuscript to BioMed Central and we will help you at every step:}

- We accept pre-submission inquiries

- Our selector tool helps you to find the most relevant journal

- We provide round the clock customer support

- Convenient online submission

- Thorough peer review

- Inclusion in PubMed and all major indexing services

- Maximum visibility for your research

Submit your manuscript at www.biomedcentral.com/submit
Biomed Central 